Revista Iberoamericana. Vol. LXIII, Núm. 181, Octubre-Diciembre 1997; 631-648

\title{
SABERES AMERICANOS: \\ LA CONSTITUCIÓN DE UNA SUBJETIVIDAD COLONIAL EN LOS VILLANCICOS DE SOR JUANA ${ }^{1}$
}

\author{
POR \\ Yolanda Martínez-SAn Miguel \\ Universidad de Puerto Rico-Rio Piedras
}

\begin{abstract}
De donde infiero, que sólo/ fue poderoso el esfuerzo/ a diferenciar los hombres, / que tan iguales nacieron, / con tan grande distinción/ como hacer, siendo unos mesmos, / que unos sirvan como esclavos/ y otros manden como dueños.
\end{abstract}

-Sor Juana Inés de la Cruz, "Amor es más laberinto".

\section{El DeBate colonial y postcolonial}

¿Qué define la condición colonial en el México del siglo XVII? ¿Cómo se articulan las redes de poder en esta sociedad virreinal? ¿Es acaso apropiado referirse a la situación política de América durante los siglos dieciséis, diecisiete y dieciocho como un caso extensivo de colonialismo? Estas y otras preguntas similares han sido recientemente objeto de reflexión en el campo de los estudios coloniales contemporáneos. Parecería que ante la diversidad de experiencias que definen la condición y teorización colonial, empieza a hacerse necesaria una distinción que matice las especificidades de la experiencia política y social que caracterizó la vivencia de una amplia gama de grupos raciales, étnicos y culturales que convivieron en el continente americano durante unos trescientos años. Robert Young y Jorge Klor de Alva han planteado toda una serie de cuestionamientos afines que intentan distanciar la experiencia de América de otras inflexiones más recientes de lo que se denomina actualmente como colonialismo:

To what extent is 'colonial discourse' itself a legitimate general category? It is hard to avoid the accusation that there is a certain idealism involved in its use as a way of dealing with the totality of discourses of and about colonialism. [...] But does the fact that modern colonialism was effected by European or European-derived powers mean that the discourse of colonialism operated everywhere in a similar enough way for the theoretical paradigms of colonial-discourse analysis to work equally well for them all? [...] Can we assume that colonial discourse operates identically not only across all space but also throughout time? (Young 164).

\footnotetext{
' Este artículo es parte de un estudio más amplio que incluye otros villancicos y escritos de Sor Juana. Agradezco a Emilie Bergmann, Antonio Cornejo-Polar, Georgina Sabat-Rivers y Norma Alarcón sus valiosos comentarios durante la realización de este proyecto.
} 
Siguiendo esta misma línea de reflexión, Klor de Alva ha señalado que la experiencia colonial no es aplicable al contexto americano de los siglos dieciséis al dieciocho por cuanto la ocupación española de los territorios americanos no fue vista como una presencia extranjera alienante dado el intenso mestizaje que vulneró el sistema de distinciones raciales y de origen territorial (4-5). De acuerdo a esta teorización, el colonialismo clásico entendido como la presencia de sectores europeos extranjeros que dominaron económica y políticamente territorios poblados por otros sectores nativos- no funcionaría en América porque el mestizaje creó un tercer sector mestizo que era considerado como nativo, y que se encontraba íntimamente ligado al poder metropolitano. De este modo, no se podría hablar ni de experiencia colonial clásica, ni de la independencia de América Latina en el siglo diecinueve como un proceso de descolonización equiparable a la experiencia de India o África (Klor de Alva 18-9).

$\mathrm{Si}$ bien es cierto que es necesario matizar los modos en que la experiencia americana se aproxima y se distancia del colonialismo clásico que le da su origen y primer significado al término, también es cierto que esta experiencia colonial clásica no estuvo exenta de toda una serie de modificaciones y cambios que permitieron concebir una evolución y transformación de lo que se denomina actualmente como la condición colonial y neocolonial. El trabajo de Robert Young sobre el sistema colonial británico muestra cómo estas categorizaciones del sistema colonial clásico no operaron de un modo estático en la misma experiencia de India y África que actualmente se utiliza como paradigma en la definición de este término. También demuestra cómo el mestizaje fue una parte significativa de la experiencia colonial británica(Young 142-58). Por lo tanto, parecería que no es precisamente la presencia del mestizaje, ni del proceso transculturador de imaginarios (Gruzinski 282) lo que definiría la especificidad de la experiencia colonial ni española, ni británica. Por otro lado, si bien es cierto que el peninsular no era visto como un elemento absolutamente foráneo en el espacio colonial novohispano, también se sabe que funcionaron ciertas categorías de extranjería que permitieron articular una serie de discursos criollos, mestizos e indígenas que aspiraban a probar el carácter orgánico de algunas identidades frente a la diferencia del poder metropolitano y peninsular.

El debate mismo sobre la especificidad de la experiencia colonial americana apunta a toda una serie de elementos significativos que necesitan mayor atención teórica. En particular, se hace necesario matizar la experiencia colonial para poder dar cuenta de un proceso de ocupación imperial que duró cerca de tres siglos, y que por lo tanto operó diversas transformaciones específicas que vulneraron la polaridad de ciertos discursos coloniales locales y sus contrapartes metropolitanas a nivel social, político y económico. También es necesario promover estudios que identifiquen las diversidades de la experiencia colonial para especificar, por ejemplo, cómo se experimentó el colonialismo en los centros virreinales como México y Perú en contraposición con experiencias más periféricas como las del Caribe. ${ }^{2}$

\footnotetext{
${ }^{2}$ Algunos estudiosos han comenzado también a explorar las diferencias entre el sistema colonial español y portugués. Por ejemplo, Canny y Pagden señalan que en el caso de los virreinatos de México y Perú se hizo posible la emergencia de un campo intelectual más independiente porque España permitió el establecimiento de universidades en América, algo que no ocurrió en Brasil (86-7).
} 
Éste es precisamente el tipo de intereses que han promovido una serie de estudios recientes sobre la América colonial y sus producciones culturales. ${ }^{3}$ En los mismos se postula la emergencia de un sujeto colonial americano que se diferencia de los marcos de referencia europeos, al mismo tiempo que conserva un ambiguo sentimiento de identificación y distanciamiento con la metrópoli. Este sinuoso proceso de identificación y distanciamiento produce todo un discurso que define el espacio del virreinato no como territorio ni colonia de España, sino como recinto equiparable, aunque no independiente, a la metrópoli española (Canny y Pagden 61). De acuerdo a esta caracterización del virreinato, los criollos tenían igualdad de derechos frente a los peninsulares, y con ello lograron justificar la legitimidad de sus reclamos para ocupar puestos públicos oficiales. ${ }^{4}$

Sin embargo, la mayoría de los estudios recientes siguen insistiendo en la identificación del discurso criollo más temprano con la formación de una conciencia protonacionalista que desembocará en las luchas de independencia del siglo diecinueve. Este énfasis tan significativo en la formación del discurso nacionalista y en la búsqueda del origen de una identidad latinoamericana termina imponiendo sobre la época colonial toda una serie de teleologías de lectura que desplazan conflictos más específicos de la experiencia colonial per se. ${ }^{5}$ Lejos de explorar la conflictividad inherente en la formación del sujeto y la epistemología colonial, estos estudios superponen una narrativa esencialmente armónica y monológica que borra las incongruencias de una experiencia de hibridez e interacción

\footnotetext{
${ }^{3}$ Me refiero a las compilaciones de Nicolas Canny y Anthony Pagden, Colonial Identity in the Atlantic World, 1500-1800; y René Jara y Nicholas Spadaccini, 1492-1992: Re/Discovering Colonial Writing y Amerindian Images and the Legacy of Columbus. Estos trabajos se han nutrido de los debates más recientes en los estudios coloniales y postcoloniales iniciados por el estudio de Edward Said Orientalism - sobre los modos en que los campos de estudios occidentales están conformados por la experiencia colonial misma que aspiran a explicitar. Para un buen resumen del estado más reciente de este debate, ver el capítulo de Robert Young "Colonialism and the Desiring Machine", que se incluye en Colonial Desire, Hibridity in Theory, Culture and Race, y donde se resume el trabajo crítico de Said, H. Bhabha, G. Spivak y Delueze y Guattari en el estudio de los discursos coloniales y postcoloniales.

${ }^{4}$ Este deseo de igualdad entre los peninsulares y los sectores criollos genera todo un patrón de mímesis de los modos y prácticas metropolitanos en la sociedad virreinal. Homi Bhabha ha trabajado este proceso de mímesis como modo de resistencia y sincretismo que termina desnaturalizando la autoridad de la ley colonial y desarticulando las identidades duras, de modo que se desestabilizan los esfuerzos localizadores del sujeto colonizado en las redes de representación colonial (125-133). De este modo Bhabha postula la mímesis como estrategia dinámica que no necesariamente implica la asimilación monolítica del colonizado, sino que puede generar sus respuestas diferenciadas para agenciar una ley alterna.

${ }^{5}$ Este tipo de estudios también privilegia a un sector específico de prácticas culturales - la criolla por sobre toda una diversidad de sectores y prácticas indoamericanas, africanas y mestizas que coexistían en el mismo espacio colonial de modo desigual y fragmentario. Por otro lado, Américo Paredes ha propuesto una privilegización del sector mestizo y sus prácticas culturales en el estudio del surgimiento del sentimiento mexicanista en "Mexican Legendry and the Rise of the Mestizo: A Survey". Este tipo de desplazamientos en el núcleo de los estudios de los discursos de formación nacional evidencian cómo cualquier intento de homogeneización resulta en la marginación de toda una serie de otros sectores que participaron o se distanciaron del discurso nacionalista oficial en los países latinoamericanos.
} 
cultural y política que no se puede reducir ni a partir del modelo nacionalista, ni a partir del acercamiento marxista clásico (Spivak 206).

Es a partir de este debate mismo que propongo una lectura de los textos de Sor Juana para identificar en los mismos la constitución de diversas instancias de la subjetividad colonial en la Nueva España del siglo diecisiete. Para ello me concentro particularmente en la noción de la raza como una suerte de eje a partir del cual los textos de Sor Juana despliegan toda una serie de posiciones coloniales que aspiran a acceder a un saber oficial eurocéntrico y metropolitano. ${ }^{6}$ La raza viene a servir como una categoría inicial en el proceso mismo de la postulación de una identidad y/o alteridad entre el sujeto colonizador y el colonizado, por cuanto la misma provee una marca corporal muy visible que permite rastrear y localizar las diferencias: "Racism sums up and symbolizes the fundamental relation which unites colonialist and colonized. [...] colonial racism is so spontaneously incorporated in even the most trivial acts and words, that it seems to constitute one of the fundamental patterns of colonialist personality" (Memmi 70). Robert Young también ha resumido esta relación fundamental entre colonialismo tardío y el racismo como sigue: "It was through the category of race that colonialism itself was theoretically focussed, represented and justified in the nineteenth century, it was also through racial relations that much cultural interaction was practised" (180). Aun reconociendo la distancia que media entre el modelo colonial del siglo diecinueve al que hace referencia Young y el contexto de la Nueva España en el que escribe Sor Juana, lo cierto es que la categoría de raza puede servir como un punto de partida para explorar las complejidades de una experiencia política y social que todavía no se planteaba la existencia de un sujeto criollo y nacional que sintetizara las nociones de diferencia tradicionales que más tarde definirían el debate político entre Latinoamérica y los centros metropolitanos. Esto es así porque el límite racial se articula mucho más temprano que la diferencia política en el contexto colonial, sobre todo por la experiencia misma de contacto entre sujetos de diversas fisonomías, culturas y etnias que fue tan notable en la Nueva España. ${ }^{7}$

\footnotetext{
${ }^{6}$ Utilizo la raza como punto de partida por considerarlo un eje paradigmático y consistente en la constitución del poder colonial. Para ello me baso en los trabajos de Albert Memmi, de Frantz Fanon y Aimé Cesaire en Discourse on Colonialism, que parten del racismo como discurso constitutivo del poder colonial, de modo que el contacto y mezcla racial viene a ser un límite que dramatiza el ejercicio del poder.

${ }^{7}$ La raza será también central en la postulación hegeliana de la dialéctica entre el amo y el esclavo, donde se propone que el sujeto se articula a partir del reconocimiento del otro (Fanon, Black Skins 215). Fanon elabora esta relación entre esta noción hegeliana con las concepciones de raza en el contexto colonial en su libros Black Skins, White Masks y The Wretched of the Earth. Fanon sugiere en estos trabajos que la raza pasa a ser un significante superestructural, por cuanto la raza se equipara a la clase social y económica de un individuo en el momento en que ser rico equivale a ser blanco y viceversa (The Wretched 40). Iris Zavala, en su ensayo titulado "Representing the Colonial Subject", ha revisado la taxonomía racial en el caso de la Nueva Españay ha señalado este mismo desplazamiento apuntado por Fanon en el significado del término "castas": "Etimologically, it referred to "animal species', by 1500 to 'race or lineage of men', and by 1513 to 'class, type or condition"” (335). Zavala argumenta que este tipo de desplazamientos también pone en evidencia cómo la taxonomía racial de la Nueva España fue un modo de diferenciar al sujeto colonial mediante la animalización de su cuerpo y su raza. Para más información, ver este ensayo de Zavala.
} 
Los textos de Sor Juana trabajan precisamente este proceso identificatorio y delimitador a partir de la representación de numerosas voces coloniales que pugnan por acceder a un espacio epistemológico oficial en la época. Y es precisamente a partir de la identificación racial que sus villancicos distribuyen los espacios que le corresponde a cada una de estas voces en el espacio cognoscitivo de la Nueva España. En este sentido, mi lectura se desplaza más bien hacia el conflicto inter-subjetivo intelectual como reflejo de las pugnas políticas y sociales más amplias que caracterizaban la condición colonial novohispana.

\section{LOS VILLANCICOS Y LA CONSTRUCCIÓN DE UNA "EPISTEMOLOGÍA INTER-CULTURAL"}

El pueblo que llenaba las catedrales la oía, la entendía y sentía que se identificaba con esa que era su voz. No entendía el latín de los maitines, pero sí comprendía el castellano, el náhuatl, la jerigonza de las mezclas, y la sencillez de lo que se decía, aprendiendo por ello su gran lección de teología (Muriel, Cultura femenina 159).

La mayoría de los estudios críticos sobre los villancicos de Sor Juana han destacado su carácter popular y su capacidad representativa de las voces marginadas de la sociedad colonial. ${ }^{8}$ El término "villancico" se origina como "un diminutivo de villano, el aldeano o rústico -y su cantar, tañido, o baile característico, o bien su imitación ya más o menos artificiosa" (Cruz, OC II XI). De ahí que resulte claro el vínculo de este género con el habla coloquial y la representación de los sectores populares de la sociedad metropolitana. Originalmente el contenido de estas composiciones podía ser sacro o profano, y su interés primordial era la representación del habla rústica, siguiendo el modelo del "sayagüés" que Encina había elaborado en sus breves obras fársicas. No será hasta más tarde que el villancico se institucionaliza como composición religiosa que se canta en la iglesia durante la Navidad y otras festividades (OC II XIII). Ya para los años entre 1660 y 1750 el villancico se ha especializado para convertirse en un conjunto de ocho a diez villancicos que trataban un tema religioso y que se representaban exclusivamente durante los Maitines en las fiestas litúrgicas. La mayoría de los villancicos finalizaban con una "ensalada" donde se representaban la multiplicidad de voces de los sectores marginales de la sociedad metropolitana (XVIII).

Es precisamente esa estructura del juego de villancicos la que quiero destacar en mi lectura de algunos de los textos de Sor Juana. Es importante recordar aquí que el propósito principal de estos villancicos religiosos era transmitirle al pueblo que se congregaba en la iglesia alguna enseñanza sobre el dogma o la creencia católica. De ahí que la inclusión de voces "populares" apunte hacia lo que el epígrafe, que incluyo de Muriel, destaca como la necesidad de identificar los registros y modos de expresión del pueblo para transmitirle una enseñaza doctrinal que los unificaba.

\footnotetext{
${ }^{8}$ Me refiero a los trabajos de Josefina Muriel, Luis Leal, Dario Puccini y Octavio Paz citados en la bibliografía, por mencionar algunos de los estudios más conocidos. Rosa Valdés Cruz, Karl Vossler y Gerard Cox Flynn en Sor Juana Inés de la Cruz se oponen a esta visión reinvindicadora y subversiva de la representación de otros sectores subalternos en la obra de Sor Juana.
} 
De acuerdo a este propósito "unificador", los villancicos comenzaban con la voz centralizadora de la fe católica metropolitana y progresaban a lo largo del juego hacia una dispersión de voces que culminaban con la "ensalada" o mezcla de diversas voces populares. El villancico ensayaba, a lo largo de sus nueve composiciones, una serie de explicaciones simultáneas, llevadas a cabo en diversos registros verbales e intelectuales, para transmitir una misma verdad doctrinal o dogmática a un público muy heterogéneo. Parecería, entonces, que los juegos de villancicos trazan en su estructura misma un viaje desde el saber católico metropolitano hasta la multiplicidad de voces de la Colonia que produce una "epistemología inter-cultural" donde el villancico es el lugar de confluencias y tránsitos de varios paradigmas cognoscitivos. Este gesto multiplicador de los paradigmas cognoscitivos es el resultado de un contexto colonial o multiracial que por medio de los contactos interculturales promovió la postulación de un nuevo paradigma epistemológico y pedagógico que negociaba el lugar del sujeto subalterno dentro de la jerarquía Europa/América.

El juego de villancicos dedicados a la "Asunción" en 1676 abre con una competencia entre el cielo y la tierra por ver cuál obtuvo el mayor favor divino. El primer villancico introduce el tema de la Virgen a partir de una impresionante alabanza: "pues el Vientre de María/es mucho mejor que el Cielo" (Cruz, $O C$ II 4). De ahí el juego de villancicos se desdobla en diversas alegorías, que destacan las virtudes de la Virgen María. El segundo villancico está redactado en latín, y en el mismo se alaba su rol como madre de Cristo y se describe su ascención al cielo ante la admiración humana. El tercer, cuarto y séptimo villancico desarrollan tres alegorías relacionadas con distintos campos del saber: el saber universitario, en donde la Virgen logra presentarse exitosamente en la oposición para la Cátedra de Prima de Teología; el saber musical, en el que la Virgen se distingue como "Maestra Divina,/ de la Capilla Suprema" (Cruz, $O C$, II 7) y el arte de la retórica, pues "María sabe enseñar/ el arte de bien decir" (Cruz, OC II 13). ${ }^{9}$ En estos tres villancicos se destaca la capacidad pedagógica y académica de la Virgen, que se ubica en la posición de "Maestra" que puede impartir efectivamente una enseñanza al público religioso. En este sentido la alegoría teológica se transporta a un contexto pedagógico y educativo que es también central en el gesto del villancico que se representa en la iglesia.

Dejando de lado los ecos que esta caracterización de la Virgen tiene con la defensa del estudio y enseñanza femeninos desarrollados en la Respuesta a Sor Filotea, es importante destacar cómo el villancico vincula saber religioso y conocimiento secular en el modo mismo en que caracteriza las virtudes de la Virgen María. Este vínculo entre saber institucional y religión se desarrolla también en el juego de villancicos por vía de los diversos registros del lenguaje que se incluyen en el texto. Además del castellano y el latín que abren el juego de villancicos, encontramos el lenguaje heterodoxo del "Cantar de los cantares" - por su entrecruce del lenguaje sexual y el amor místico- que se elabora poéticamente en el villancico cinco, así como el lenguaje popular que se incluye en los

\footnotetext{
${ }^{9}$ Este tipo de villancicos son los que Robert Ricard denomina como “doctos", pues la monja aprovecha su amplia erudición para elaborar juegos verbales que se derivan de su dominio cabal de ciertas disciplinas (33). De acuerdo a Ricard, Sor Juana elabora en su poesía religiosa dos registros, uno culto y uno popular, pero esta serie de villancicos eruditos serían un entrecruce de ambos estilos de modo que sus obras apelaban a un público más amplio.
} 
villancicos seis y ocho. De ahí el villancico elabora una descripción de la Virgen María como una guerrera de la fe:

\author{
¡Allá va, fuera, que sale \\ la Valiente de aventuras, \\ Deshacedora de tuertos, \\ Destrozadora de injurias! \\ Lleva de rayos del Sol \\ resplandeciente armadura, \\ de las Estrellas el yelmo, \\ los botines de la Luna; \\ $\mathrm{y}$ en un escudo luciente \\ con que al Infierno deslumbra, \\ un monte con letras de oro \\ en que dice: Tota Pulchra (Cruz, OC II 10-11)
}

La Virgen se equipara en estos versos con un caballero andante que defiende la fe católica. Las alusiones militares y de fuerza física desplazan la figura de la Virgen María a un campo semántico que nos recuerda que fue precisamente la religión el pretexto para justificar la dominación militar de la América colonial, así como la Reconquista española. De este modo se añade la lucha militar y física colonial al espacio de los diversos saberes universitarios y retóricos a partir de los cuales se desarrolla el catálogo de virtudes de la Virgen. Por otro lado, esta asociación con la empresa militar vuelve a ubicar a la Virgen en el espacio intersticial de la oposición entre fuerza y razón, regresando así a la apertura del juego de villancicos que presenta a la Virgen como figura debatida entre el cielo y la tierra. La Virgen ocupa, entonces, ese lugar intermedio que vulnera categorizaciones de género sexual, jerarquías del saber, clasificaciones teológicas y prácticas de poder.

El juego de villancicos cierra con una "Ensaladilla" que se divide en tres registros vocales: la Reina, los Negros y los Indígenas. Esta diversificación de voces apunta hacia la ampliación de registros semánticos y lingüísticos que aspira a transmitir esta alabanza de la Virgen a un público heterogéneo. Con la entrada de la "Plebe humana" en el villancico culmina el viaje que se traza desde el castellano y el latín inicial hasta el náhuatl con que se cierra el juego de villancicos. La "Introducción" de este villancico cumple con esta función ampliadora de las voces que pueden participar en el canto religioso: "A la aclamación festiva/ de la Jura de su Reina/ se juntó la Plebe humana/ con la Angélica Nobleza" (Cruz, $O C$ II 14). De ahí el villancico se divide en tres canciones. El primer hablante es una "Reina" que ofrece obediencia a la Virgen a cambio de que ésta proteja la paz humana y defienda sus vidas contra la violencia. Nótese que la Reina es esa primera instancia de la "Plebe humana" que se congrega en la iglesia, de modo que se destaca la lateralidad del sujeto femenino en la estructura del poder secular. Después del canto de la Reina entran los negros esclavos, quienes alaban a la Virgen María pero lamentan que ésta ascienda a los cielos dejándolos solos en la labor forzada de la esclavitud:

1. Cantemo, pilico, que se va las Reina, y dalemu turo
-Cantemos, Perico que se va la Reina, y démosle todos 
una noche buena.

2. Iguale yolale,

Flacico, de pena, que nos deja ascula a turo las Negla.

1. Si las Cielo va

y Dioso la lleva,

¿pala qué yolá,

si Eya sa cuntenta?

2. Déjame yolá,

Flacico, pol Eya,

que se va, y nosotlo

la Oblaje nos deja. (Cruz, $O C$ II 15-16) una noche buena.

-Igual es llorar,

Blasico de pena:

nos deja a oscuras

a todos los Negros.

- Si al Cielo se va

y Dios se la lleva,

¿para qué llorar,

si Ella está contenta? [...]

-Déjame llorar,

Blasico, por ella

que se va, y a nosotros

el Obraje deja.

Lo primero que es notable en el texto es la marca lingüística que separa el español accidentado de los negros esclavos del castellano que abre y predomina en la mayoría de los villancicos de este juego. Esta representación del habla particularizada del negro contrasta con otras representaciones estilizadas del habla indígena que aparecen en las loas a los autos sacramentales de Sor Juana. ${ }^{10}$ Lo interesante es que el villancico se acerca al público de la iglesia por medio de la entrada de personajes marginales que presentan sus respetos a la Virgen que asciende al cielo, a la misma vez que lamentan el distanciamiento de la religión católica de los sufrimientos de la vida esclava. La elaboración del canto esclavo en dos voces, una que parece conformarse con la partida de la Virgen, y otra que lamenta su distancia y olvido de los negros esclavos, trabaja una polifonía de opiniones que no permite homogeneizar la participación del negro esclavo en el rito religioso. El estribillo final de esta sección unifica ambas voces por medio de la identificación racial de la Virgen con los esclavos: "- ¡Uh, uh, uh, / que non blanca como tú,/ nin Pañó que no sa buena,/ que Eya dici: So molena/ con las Sole que mirá!" (Cruz, OC II 16). ${ }^{11}$ Parecería que la única manera en que se puede lograr una unión total es desvinculando a la Virgen de la raza blanca y española que la asocia con el poder esclavizador virreinal, y asociándola con la raza negra. De este modo el villancico alude muy veladamente hacia el gesto sincrético que transformaba los santos y figuras divinas católicas en equivalentes de deidades africanas. La apertura del texto a este tipo de transformación racial de la Virgen se inserta y equipara a toda la serie de otras transformaciones de la Virgen - ya en Maestra, o en caballera andante - por medio de las cuales se alegorizaba la enumeración de sus virtudes. Así el texto también ubica el sincretismo en un contexto evangelizador, de modo que la transformación de la Virgen en morena no sólo la hace potable para un público esclavo, sino que la convierte en un motivo de confluencia con las prácticas religiosas oficiales de la colonia. De este modo el sincretismo - aludido aquí en su dimensión racial - se convierte en una más de las estrategias evangelizadoras que unifican las diversas voces del villancico en la comunidad de la fe.

\footnotetext{
${ }^{10}$ Estudio este tema con más detenimiento en mi ensayo "Articulando las múltiples subalternidades en el Divino Narciso".

11 "¡Uh, uh, uh,/ que no es blanca como tú,/ni Español, que no es bueno;/ que Ella dice: Soy Morena/ porque el Sol mirado me ha!"
} 
Por otro lado, es importante destacar que esta representación onomatopéyica de la voz del negro si por un lado intenta acercarse a la individualidad del sujeto representado, por otro evidencia un desconocimiento y distanciamiento del sujeto negro, al asumir su modo diferente de hablar como sonido rítmico más ligado al cuerpo. De ahí que el lenguaje onomatopéyico señale precisamente el límite del conocimiento mismo sobre el esclavo, a quien se le abre un espacio dramático muy frágil por su vinculación con el humor y la burla fársica (Valdés-Cruz 209). El negro esclavo no entra en el villancico en el mismo nivel racional y epistemológico que el texto latino o las alegorías pedagógicas que se presentan en castellano, sino como ritmo y musicalidad que varían el cántico del villancico.

Sin embargo, la crítica social que asoma en los versos cantados por los negros esclavos evidencia una mentalidad crítica que se resiste al sistema social y político vigente y es capaz de transformar los referentes metropolitanos para un uso muy específico de su sector social. La identificación de la raza como el valor que polariza los espacios sociales es también otro índice de cómo el sujeto negro entra a participar en el catálogo de alegorías y debates a partir de los cuales se tematizan las virtudes de la Virgen María.

Por último, este juego de villancicos cierra con un tocotín en náhuatl que pide a la Virgen que no olvide a sus devotos indígenas y la ubica en el lugar de mediación entre Cristo y la humanidad de un modo muy similar al tradicional culto mariano metropolitano. La Virgen ocupa, entonces, ese espacio de intercesión que permite la salvación de los fieles indígenas: "Ea, pues, por las gentes/ suplícale:/ y si no quiere,/ recuérdale/ que tu carne/ Tú le diste,/ tu leche/ bebió, si soñaba/ también pequeñito." (Cruz; OC II 365). Lo interesante de este cierre es que permite la entrada del "Mejicano lenguaje" (Cruz, OC II 16) que transmite, por medio de la extrañeza de la lengua para un público metropolitano y criollo, un contenido bastante típico de la poesía religiosa medieval y renacentista europea. Este gesto también parece ubicar al indio como sujeto más asimilable a la tradición religiosa europea que el africano sincretizador. De este modo el villancico también diferencia los espacios que ocupan los sujetos indígenas y africanos para destacar las jerarquías que informaban las nociones de raza en la sociedad novohispana. Por otro lado, es precisamente este cierre en una lengua diferente lo que culmina el proceso epistemológico inter-cultural con el cual caractericé los juegos de villancicos al comienzo de esta lectura. El texto se mueve del marco del castellano y el latín hacia registros disciplinarios, coloquiales y populares, para luego entrar en el español accidentado de los negros esclavos y termina cruzando de un lenguaje a otro con la entrada del náhuatl al texto. La estructura del texto se puede resumir como sigue:

Villancico I: Apuesta del Cielo y la Tierra

Villancico II: Ascención de María

Villancico III: Alegoría Universitaria

Villancico IV: Alegoría Musical

Villancico V: Alusión al Cantar de los cantares

Villancico VI: Alegoría Guerrera

Villancico VII: Alegoría Retórica

\author{
Castellano \\ Latín \\ Castellano y Latín \\ Vocabulario Disciplinario \\ Castellano y Latín \\ Vocabulario Disciplinario \\ Castellano \\ Español coloquial \\ Castellano \\ Vocabulario Disciplinario
}


Villancico VIII: Ensaladilla

Castellano, habla negroide y náhuatl

El cierre del texto en otro lenguaje sugiere un viaje que comienza en la metrópoli y termina en América, manteniendo la religión como el vínculo que aúna todos los modos diversos de expresión y de articulación de saberes sobre un mismo aspecto: la Virgen María y sus virtudes. El texto recupera, entonces, la multiplicidad de saberes disciplinarios, raciales y regionales que "confluyen" en el espacio religioso.

Una estructura muy similar se observa en los villancicos dedicados a la "Concepción" (1676), "San Pedro Nolasco" (1677); "San Pedro Apóstol" (1677); “Asunción" (1679); “Asunción"(1685); y "San José”(1690). La similaridad en la estructura permite sugerir que el villancico es el género por medio del cual se trazan puntos de contacto y de desencuentros entre los campos de saber religioso y secular, metropolitano y colonial. Por medio de la empresa evangelizadora el texto se desdobla en una multiplicidad de instancias lingüísticas y saberes que cuestionan las jerarquías sociales, raciales e institucionales que consolidaban el poder colonial. Este cuestionamiento, no necesariamente subversivo, apunta hacia un deseo de ampliar los espacios de debate y de conocimiento para incluir las variantes regionales no sólo americanas sino europeas.

Por ejemplo, hay un par de juegos de villancicos que finalizan con las voces de un vasco y un portugués como las voces "disonantes" de sus ensaladillas. Éste es el caso del villancico número 249 del juego dedicado a "San Pedro Apóstol" (1677):

Timnoneyro, que governas

la Nave do el Evangelio,

e los tesouros da Igrexa

van a tua maun sugeitos:

mide a equinoccial os grados

e do Sol o apartamento,

pois en todo o mundo tein

de servir tuo deroteiro (Cruz, $O C$ II 57).

La voz del portugués se introduce justo después de que ha cantado un "mestizo" elogiando a San Pedro Apóstol. Del mismo modo, en el villancico número 274 del juego dedicado a la "Asunción" (1685) se unen el castellano, el latín, la voz de un negro esclavo y la voz de un vasco, todas alabando diversas virtudes de la Virgen. Esta mezcla de registros en un mismo villancico alude no sólo a una diversificación de los registros y modos del saber religioso, sino que también legitima y equipara los diversos registros frente a la creencia religiosa compartida. El vasco es quien cierra este texto, en una composición que mezcla el castellano y el vascuence:

Aquí en Vizcaya te quedas:

no te vas, nere Biotzá; *

y si te vas, vamos todos,

¡ba goaz! [...]*

Guatzen, Galanta*, contigo; guatzen, nere Lastaná:* *corazón mío

*vámonos

${ }^{*}$ iNosotros en pos de ti, contigo hermosa

${ }^{*}$ ¡Nosotros en pos de ti, oh Amada mía! 
que al Cielo toda Vizcaya

has de entrar.

La inclusión de voces "regionales" de procedencia europea en el mismo lugar en que se incluyen las hablas regionales coloniales sugiere una equiparación de las voces indígenas y negras como otras modulaciones locales - o "provinciales" - del circuito metrópolicolonia. ${ }^{12}$ Aunque la mayoría de los villancicos mantienen las marcas de poder y jerarquía al identificar las voces indígenas y negras, parecería que la voluntad del texto es integrarmás que diferenciar y separar completamente-- los saberes americanos al contexto oficial religioso y político. En este sentido, el sujeto colonial se ubica en los textos como expresión de una identidad, lengua y saber regional que se puede integrar al saber metropolitano del mismo modo que se integra ilusoriamente en el espacio religioso que los villancicos enuncian.

Es necesario destacar que en este mismo villancico número 274 se presenta la voz negra como registro más accesible al público que el latín oficial en el que se llevaban a cabo algunos ritos y oraciones oficiales de la Iglesia Católica. La "ensalada" abre con un diálogo a dos voces donde se presentan unas coplas en latín que inician los cantos. En estas coplas se alaba a la Virgen y se pide su protección. Inmediatamente finaliza esta canción, interviene una tercera voz que sugiere un cambio de registro porque no entiende el saber que se transmite por vía del latín:

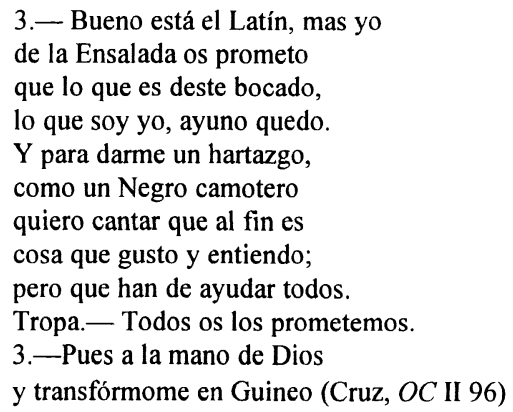

De este modo se cuestiona el alcance universal del latín como lengua para transmitir un saber, y se legitima el habla negra como modo de comunicar un saber religioso a un público más masivo, quien también participa activa y colectivamente en la construcción de esta voz. Por otro lado, el texto destaca la representación de la voz negra como constructo

${ }^{12}$ Cenny y Pagden han destacado cómo existía en la Nueva España este deseo de equipararse a una provincia metropolitana para adquirir los mismos derechos que los peninsulares que vivían en América (64). La contraparte de americano es "europeo" y no necesariamente "español", quien no era visto completamente como extranjero en algunos de estos textos coloniales (79). En este sentido se puede decir que el sujeto criollo buscaba equipararse al peninsular más bien en cuanto a la legitimidad de su ciudadanía en América y no como sujeto patriótico totalmente independiente o diferenciado del espacio metropolitano. 
y como estrategia para alcanzar una audiencia más amplia. Al mismo tiempo, el negro que presenta sus respetos a la Virgen le trae una ofrenda de toda una serie de alimentos, detalle que vuelve a aludir a un sincretismo de creencias católicas y africanas como parte del proceso de aprendizaje intercultural. El negro Antón ofrece sus respetos a la Virgen María, pero sus modos y rituales todavía muestran un entrecruce con los ritos africanos prohibidos en la Colonia. ${ }^{13}$

Este doble movimiento de inclusión y cuestionamiento termina por presentar una noción pedagógica que se basa en la multiplicidad de registros porque reconoce la heterogeneidad cultural, racial y cognoscitiva que resulta irreductible a un solo lenguaje o un solo saber. De este modo la empresa de la evangelización y colonización masiva de América resulta vulnerada por la epistemología inter-cultural misma que traza el villancico, y que reconoce la variedad como constitutiva del nuevo saber americano y europeo. La transformación que se opera en el espacio subjetivo e intelectual no es privativo de América o España, sino que incluye a los otros países europeos, como lo insinúa la inclusión de la voz de un portugués en la alabanza unificada de la Virgen María.

Por último, quisiera comentar el "Juguete" incluido en el villancico número 299 que forma parte del juego dedicado a "San José" (1690). En esta breve composición se presenta una adivinanza de cuál fue el oficio de San José y que resulta interesante porque la misma termina con la participación de un indio y un negro que presentan adivinanzas que se salen del registro del resto de los enigmas presentados en el texto. El texto presenta inicialmente cuatro voces que proponen diversos oficios para San José: pastor, labrador y carpintero. Cada participante es apoyado y negado por dos voces que se contradicen: " 1 - ¡No fue tal!/ 4-Si fué tal!" (Cruz, OC II 142). La voz final que cierra esta primera parte del juguete lo presenta como "Patrón/ Protector y Abogado" de España y con un guiño humorístico se cierra la primera parte de las adivinanzas. Es en ese momento que interviene el indio y presenta su adivinanza:

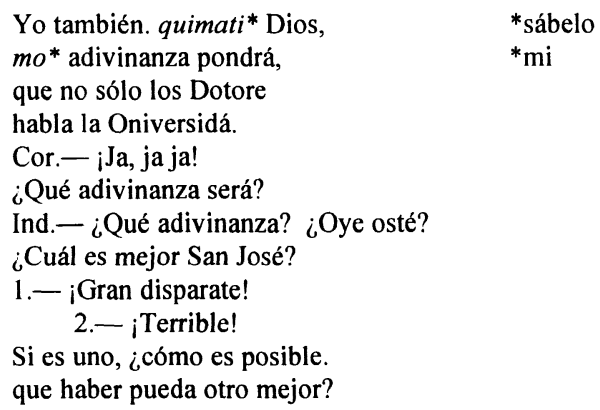

\footnotetext{
${ }_{13}^{13}$ Para más información sobre la situación de los negros esclavos en la sociedad novohispana ver el libro de Solange Alberró, especialmente la sección titulada "Negros y mulatos: La integración dolorosa"; y el artículo de Rosa Valdés Cruz, que menciona la conspiración de negros en México en 1537 y la fundación de palenques cimarrones en 1609 como referentes importantes para entender el modo en que Sor Juana representa la voz del negro en su poesía.
} 


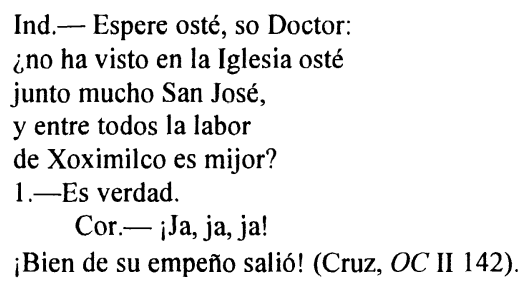

En primer lugar, hay que destacar el cambio abrupto de registro. El indio pasa del debate de los "oficios" de San José a debatir cuál es la mejor "labor" artesanal en la representación de San José. Por medio de la labor artesanal el indio se inscribe dentro del proceso representativo que el juego de villancicos despliega, pues recordemos que muchas de estas artesanías religiosas eran hechas por indígenas diestros.

Este desfase de "registros" en la adivinanza se fundamenta en un juego semántico que aprovecha la multiplicidad de significados de "oficio" y "labor". La "confusión" del indio proviene de su asociación de ambos términos con su significado ligado al "trabajo". De ahí que el indio se inscriba en el juego de adivinanzas por medio de su participación como "obrero" al servicio del colonizador. En el desliz semántico se inscribe también una relación de poder que se localiza en el "trabajo" indígena que se ha refuncionalizado al servicio de la comunidad peninsular y no de la comunidad indígena. ${ }^{14}$ Sin embargo, por medio de su "transformación" sincrética del santo en su performance artesanal, el indio vuelve a reinscribir el trabajo en una economía comunitaria local y virreinal que vuelve a entrelazar ambos contextos en un circuito colonial.

Este desplazamiento de "oficio" a "labor" provoca la risa de los miembros del coro que toman la intervención del indio como una broma. Esta risa, que casi llega a la ridiculización, se contiene por medio del cierre de la adivinanza con la legitimación que el coro hace de la participación del indio. En este sentido el texto se ve en la necesidad de justificar la entrada del registro desfasado del indio, evidenciando que su "saber" y su presencia no son bien recibidos por el resto de las voces que dialogan en el villancico. Esta representación jocosa y distanciada muestra algunos de los problemas específicos que esta integración ideal de saberes entraña, y que se sugiere en la estructura misma del villancico.

Por otro lado, es importante notar cómo el español accidentado del indio se diferencia del habla negra, de modo que opera un proceso particular de extrañamiento entre el habla indígena y negra que le sucede en el texto. Además de añadir palabras del náhuatl, se notan una serie de cambios vocálicos específicos que se diferencian de la confusión de otras consonantes por la "l", y del uso de lenguaje onomatopéyico y rítmico que se repite en los versos: "lele, lele, lele, lele" que definen el habla africana (Cruz, OC II 143). Este tipo de

${ }^{14}$ Serge Gruzinsky ha señalado cómo cuando la mano de obra indígena se puso al servicio del conquistador ocurrió una profunda transformación que convirtió el trabajo de una actividad regulada que producía bienestar físico y social en explotación de la capacidad laboral de la comunidad indígena (86). Con esta adivinanza el indígena redefine el trabajo para insertar su comunidad en el nuevo cuerpo de creencias cristianas por medio del mismo oficio artesanal que está al servicio del orden colonial. 
especificidad de lenguajes muestra un deseo de mantener presentes unas diferencias lingüísticas en el texto que implican a su vez diferencias cognoscitivas y subjetivas. Asimismo, Moraña ha notado cómo estas voces marginales que se incluyen en el villancico no hablan entre sí, aludiendo de este modo a la segregación social de estos dos grupos étnicos en el orden virreinal americano $(142,148)$. De este modo, el texto también replica en su estructura los lugares específicos que se le asignaba a estos dos sectores sociales en los discursos religiosos y culturales.

Sin embargo, y pese a la problemática inserción del indio en la adivinanza, lo interesante es que el cierre del texto termina cuestionando el alcance absoluto del saber universitario, puesto que el indio, y más tarde el negro, tienen otros saberes que aportar que no están contenidos en el registro institucional ni disciplinario del villancico. La participación del negro opera otro desplazamiento e inserción muy particular de la serie adivinatoria, pues es la raza el significante que se destaca en su intervención:

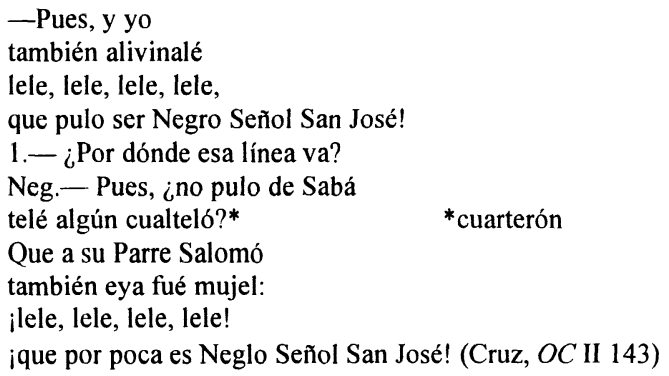

El negro esclavo sugiere que San José puede tener sangre negra, de modo que se disminuye la distancia racial entre el santo y la población africana. La raza sirve aquí de espacio de inserción por vía del mestizaje, que era una realidad significativa de la experiencia colonial novohispana. El "Juguete" parece sugerir que por vía del mestizaje, la participación artesanal y la entrada al campo epistemológico por vía del debate se puede postular una nueva relación entre los diversos polos de la realidad colonial. Asimismo, el recorrido por los diversos juegos de villancicos pone en evidencia la multiplicidad de jerarquías y voces que coexisten en el circuito de poder virreinal y metropolitano.

\section{Subjetividades COloniales y LA MUltiPlicidad Del SABER}

Para finalizar quiero regresar al epígrafe con que se abre el primer capítulo. En "Amor es más laberinto" se incluye una larga intervención de Teseo que ha llamado la atención de los estudiosos de Sor Juana, porque parece una crítica bastante abierta al poder metropolitano sobre los sujetos de la Nueva España. ${ }^{15}$ En su disquisición Teseo se presenta ante el Rey

\footnotetext{
${ }^{15}$ Gerard Cox Flynn, en su tesis titulada A Revision of the Criticism of Sor Juana Inés de la Cruz, destaca que esta intervención de Teseo parece contradecir las ideas imperantes en la época sobre la monarquía (382). Sin embargo, lo que Teseo cuestiona es el dominio de un país - y su monarcasobre otro, lo que parece cuestionar más bien el orden colonial y no el orden monárquico en sí.
} 
de Creta y legitima su valor individual porque sus logros son producto de su valentía y su mérito y no de su herencia o linaje. Esta defensa de la nobleza de acción por encima de la nobleza de sangre - tema que también fue ampliamente tratado en diversas obras de Lope, Tirso y Calderón - culmina con una explicación de la esclavitud humana como producto de la mayor fuerza que unos ejercen sobre otros, de modo que se contraviene la inclinación natural humana a la libertad. Esta reflexión vuelve a vincular la capacidad racional humana con la inclinación natural a la libertad, mientras la opone con la esclavitud que se fundamenta en la fuerza física: ${ }^{16}$

\author{
Porque pensar que por sí \\ los hombres se sometieron \\ a llevar ajeno yugo \\ $y$ a sufrir extraño freno, \\ si hay causas para pensarlo \\ no hay razón para creerlo; \\ porque como nació el hombre \\ naturalmente propenso \\ a mandar, sólo forzado \\ se reduce a estar sujeto; \\ $\mathrm{y}$ haber de vivir en un \\ voluntario cautiverio \\ ni el cuerdo lo necesita \\ ni quiere sufrirlo el necio: ... (Cruz, $O C$ IV 225)
}

Partiendo de esta reflexión se puede ubicar la condición colonial como uno de los modos de esa subordinación humana que responde al ejercicio de la fuerza física por sobre la racionalidad humana. Los textos que he analizado destacan precisamente esa pugna entre jerarquías humanas y la legitimación de una capacidad intelectual y racional colonial que se equipara textual y epistemológicamente con el campo de saber metropolitano. Tal parece que para Sor Juana uno de los modos de romper con el circuito de poder colonial que esclaviza y somete artificialmente a unos sujetos a la autoridad y control de otros es mediante la diversificación del discurso epistemológico y pedagógico que animó el proyecto de

\footnotetext{
${ }^{16}$ En este texto Sor Juana se distancia de la concepción aristotélica que justificaba la esclavitud humana al postular que los esclavos eran intelectualmente inferiores a sus dueños. De acuerdo a Aristóteles, la esclavitud no era contraria a la naturaleza porque era producto de la falta de raciocinio individual del esclavo, que como tal pasaba a ser una propiedad viviente de su amo (27-8). Para más información sobre este tema véase La política, donde se incluye una disquisición sobre la esclavitud. Sor Juana no hace en sus textos esta distinción, y ve la esclavitud como un dominio por medio de la fuerza que contraviene la razón humana y los designios de la naturaleza. Sin embargo, hay que tener cuidado con este texto, pues Teseo se refiere a la esclavitud que entraña el dominio político de un país sobre otro - como es el caso del dominio de Creta sobre Atenas por medio del tributo obligatorio de ciudadanos que eran entregados al Minotauro-y no a la esclavitud fundamentada en la diferencia racial y/o social y que implicaba la desubjetivación de un grupo humano que no era considerado ciudadano de la sociedad de un determinado país. Por eso es que nuestra lectura utiliza este pasaje como una alusión comparable a la situación colonial americana, entendiendo la misma específicamente como una forma de dominio forzado de un territorio por miembros de otro país.
} 
conquista y colonización. Me refiero particularmente al discurso religioso y evangelizador que se utilizó como justificación inicial para la esclavización de amplios sectores de la sociedad novohispana. Por medio del discurso religioso en su función pedagógica es que Sor Juana articula un proyecto diversificador que cuestiona el dominio universal del método epistemológico secular y religioso que articulaba la interacción colonial desde sus inicios. Mediante el gesto multiplicador de registros y lenguas, de puntos de vista y de procesos hermenéuticos, la escritura de Sor Juana logra ubicarse precisamente en el intersticio de este conflicto intercultural y cognoscitivo para proponer un nuevo proceso de intercambio de saberes que amplíe los espacios autorizados del saber y que reconozca la necesidad de legitimar ciertas identidades locales novohispanas para transformar el espacio del poder metropolitano y virreinal. Entre la fe y la razón, el escolasticismo y el humanismo, la metrópolis y la colonia, los textos de Sor Juana destacan el proceso de ese viaje que vinculó de un modo desigual y problemático a una diversidad de subjetividades que todavía no habían logrado entablar un diálogo dirigido a la comprensión mutua de sus referentes y límites culturales.

Además, por medio de la articulación de las distancias, las tergiversaciones, los gestos sincréticos, la intraducibilidad de ciertas lenguas, concepciones culturales o modos de aprendizaje, sus textos se concentran en las maneras en que la interacción colonial produjo una crisis cognoscitiva que no llegó a generar una epistemología intercultural eficiente. Sus juegos de villancicos evidencian la conflictividad irreductible de este proceso, pues aunque muchas voces cantan e intentan explicitar un mismo saber doctrinal en estos textos, lo cierto es que el proceso escriturario final saca a la superficie la existencia de registros y modos muy diversos de saber que no necesariamente confluyen en un diálogo armónico y transparente. Incluso cuando la aspiración es la unificación de la heterogeneidad en la comunión de creencias religiosas, lo cierto es que los villancicos también contemplan la imposibilidad de "asimilarse" sin traer consigo las marcas - ya sean raciales o lingüísticas, de subordinación física o de jerarquías intelectuales-que a su vez vuelven a diferenciar a las subjetividades que se integran en un mismo cuerpo de creencias. Incorporar es a la vez localizar en un espacio de jerarquías no necesariamente armonizables. De ahí que convicción religiosa y queja ante la injusticia social vayan a la par en muchos de estos textos doctrinarios. Saber y experiencia se vuelven a vincular en estos textos para apuntar hacia la imposibilidad de postular un sólo modo de conocer que pueda contener a la diversidad de subjetividades que intentan entablar un diálogo en los textos comentados. Las voces que intervienen en los villancicos estudiados coexisten sin asimilarse completamente, trazan puntos de contacto al mismo tiempo que evidencian los límites del proceso didáctico, de identificación comunitaria de una fe, y del proceso representativo mismo que se extraña y exterioriza en la construcción de ciertas voces que le resultan un tanto incomprensibles. En este sentido, lo que los villancicos de Sor Juana sugieren desde su estructura misma es que en América el saber surgía como un campo de múltiples negociaciones donde ya no era posible sostener un paradigma cosgnoscitivo unívoco, absoluto e ilimitado. 


\section{OBRAS CITADAS}

Alberró, Solange. "Negros y mulatos: La integración dolorosa". Inquisición y sociedad en México 1571-1700. México: Fondo de Cultura Económica, 1988. 455-487.

Aristóteles. La política. Patricio Azcárate, trad. España: Espasa-Calpe, Colección Austral, 1978.

Baudot, Georges. "El barroco mexicano, cuna del feminismo: Sor Juana Inés de la Cruz y la trova popular". Culture et societé: Andes et Meso-Amerique. Melanges en hommage a Pierre Duvois. Raquel Thiercelin, ed. Aix en Provence: Université de Provence, Service des Publications, 1991.

Bhabha, Homi. "Of Mimicry and Man: The Ambivalence of Colonial Discourse". October 28 (Spring 1984): 125-133.

Canny, Nicholas and Anthony Pagden, eds. Colonial Identity in the Atlantic World, Identity Formation in Spanish America 1500-1800. Princeton, NJ: Princeton University Press, 1987.

Certeau, Michel de. "Montaigneís 'Of Cannibalsí: The Savage I"'. Heterologies. Discourse on the Other. Minneapolis: University of Minnesotta Press, 1986. 67-79.

Césaire, Aimé. Discourse on Colonialism. New York and London: Monthly Review Press, 1972.

Cruz, Sor Juana Inés de la. Obras Completas. Alfonso Méndez Plancarte, ed. México: Fondo de Cultura Económica, 1951.

Fanon, Frantz. The Wretched of the Earth. New York: Grove Weindelfeld, 1991. Black Skin, White Masks. Londres: Paladin, 1970.

Flynn, Gerard Cox. A Revision of the Criticism of Sor Juana Inés de la Cruz. Ann Arbor, MI: University Microfilms International, 1979. Tesis Doctoral, New York University, Faculty of the Graduate School; Department of Spanish and Portuguese, 1975. Sor Juana Inés de la Cruz. Nueva York: Twayne, 1971.

Gruzinski, Serge. The Conquest of Mexico. Eileen Corrigan, trad. Cambridge: Polity Press, 1993.

Jara, René y Nicholas Spadaccini, eds. "Introduction: The Construction of a Colonial Imaginary, Columbus's Signature". Amerindian Images and the Legacy of Columbus. Minneapolis: University of Minnesota Press, 1992. 1-95.

Klor de Alva, José Jorge. "Colonialism and Postcolonialism as (Latin) American Mirages". Colonial Latin American Review 1.1-2 (1992): 3-23.

Leal, Luis. "El hechizo derramado: elementos mestizos de Sor Juana". "Y diversa de mí misma entre vuestras plumas ando": Homenaje internacional a Sor Juana Inés de la Cruz. Sara Poot Herrera, ed. México: El Colegio de México, 1993. 185-200.

Martínez-San Miguel, Yolanda. "Articulando las múltiples subalternidades en el Divino Narciso". Colonial Latin American Review 4.1 (1995): 85-104.

Memmi, Albert. The Colonizer and the Colonized. Boston: Beacon Press, 1990.

Moraña, Mabel. "Poder, raza y lengua: la construcción étnica del Otro en los villancicos de Sor Juana". Colonial Latin American Review 4.2 (1995): 139-154.

Muriel, Josefina. Las mujeres de Hispanoamérica: época colonial. Madrid: Editorial MAPFRE, 1992. 
Cultura femenina novohispana. México: UNAM, 1982.

Paz, Octavio. Sor Juana Inés de la Cruz o las trampas de la fe. México: Fondo de Cultura Económica, 1990.

Puccini, Darío. "Los 'villancicos' de Sor Juana Inés de la Cruz". Cuadernos Americanos. 24.142 (septiembre-octubre 1965): 223-252.

Paredes, Américo. "Mexican Legendry and the Rise of the Mestizo: A Survey". American Folk Legend. W.D. Hand, ed. Berkeley-Los Angeles: University of California Press, 1971. 97-107.

Ricard, Robert. Une poètesse mexicaine du XVIIe siècle; Sor Juana Inés de la Cruz. París: Université de París, Institute des Hautes Etudes de l'Amerique Latine, 1954.

Spivak, Gayatri Chakravorty. In Other Worlds: Essays in Cultural Politics. Nueva York: Methuen, 1987.

Valdés-Cruz, Rosa. "La visión del negro en Sor Juana". XVII Congreso del Instituto Internacional de Literatura Iberoamericana. Primer Tomo: El Barroco en América. Madrid: Ediciones Cultura Hispánica, 1978. 207-216.

Vossler, Karl. "La décima musa de México; Sor Juana Inés de la Cruz". Investigaciones Lingüísticas 3.1-2 (enero-abril 1935): 58-72.

Young, Robert. Colonial Desire. Hibridity, Theory, Culture and Race. Londres: Routledge, 1995.

Zavala, Iris. "Representing the Colonial Subject". 1492-1992: Re/Discovering Colonial Writing. René Jara y Nicholas Spadaccini, eds. Hispanic Issues 4. Minneapolis: The Prisma Institute, 1989. 323-348. 